\title{
Profil Kemampuan BerPiKIR KRITIS Matematis SisWa SMP DENGAN GRADED RESPONSE MODELS
}

\section{Profile of Mathematical Critical Thinking Skills Junior High School STUDENTS WITH GRADED RESPONSE MODELS}

\author{
Gita Alexandra ${ }^{1}$ dan Novisita Ratu ${ }^{\mathbf{2}}$ \\ 1Program Studi Pendidikan Matematika, Universitas Kristen Satya Wacana \\ Jl. Diponegoro No. 52-60 Sidorejo, Salatiga, Jawa Tengah, Indonesia \\ gitaalexandra09@gmail.com \\ ${ }^{2}$ Program Studi Pendidikan Matematika, Universitas Kristen Satya Wacana \\ Jl. Diponegoro No. 52-60 Sidorejo, Salatiga, Jawa Tengah, Indonesia \\ novisita.ratu@staff.uksw.edu
}

\begin{abstract}
Abstrak
Kemampuan berpikir kritis merupakan elemen penting yang harus dimiliki siswa di sekolah. Namun kenyataannya kemampuan berpikir kritis yang dimiliki siswa saat ini berada pada kategori rendah. Salah satu cara yang dapat dilakukan untuk melatih berpikir kritis adalah dengan membiasakan siswa berlatih soal untuk mengembangkan pemikirannya. Penelitian ini bertujuan untuk mendeskripsikan profil kemampuan berpikir kritis matematis siswa SMP dengan Graded Response Models (GRM). Kriteria berpikir kritis yang dijadikan acuan dalam penelitian ini adalah FRISCO (focus, reason, inference, situation, clarity dan overview). Subjek penelitian adalah 3 orang siswa SMP Pangudi Luhur Salatiga. Ketiga subjek diambil berdasarkan tiga kategori, yaitu siswa dengan kategori kemampuan tinggi yaitu subjek $A$, berkemampuan sedang yaitu subjek $B$ dan berkemampuan rendah yaitu subjek $C$. Hasil estimasi parameter kemampuan berpikir kritis matematis siswa menunjukan bahwa subjek A memenuhi kriteria (focus, reason, clarity dan overview). Subjek B memenuhi kriteria (reason dan clarity). Subjek C memenuhi kriteria (situation). Berdasarkan perhitungan estimasi parameter butir soal dengan GRM, ketiga subjek memiliki kemampuan berpikir kritis rata-rata dengan nilai kemampuan antara 1,00 sampai -1,00. Kata Kunci: berpikir kritis, graded response models.
\end{abstract}

\begin{abstract}
Critical thinking is an important element which students have in the school. However, the critical thinking in the students nowadays is in the lower level. One strategy that could improve the critical thinking is by giving and practicing the tasks to the students continually to upgrade their knowledge. This research aims to describe the students' critical thinking of mathematic skill profile in Junior High School with Graded Response Models (GRM). The criterion of critical thinking that becomes the core in this research is FRISCO (Focus, Reason, Inference, Situation, Clarify, and Overview). The subject of the research is three students of Pangudi Luhur Junior High School Salatiga. Those three subjects were taken based on three categories which are A subject (the students who have high intelligence), B subject (the students who have standard intelligence), and $C$ subject (the students who have low intelligence). The estimate parameter result of students' mathematics critical thinking shows that the $A$ subject fulfilled the criterion (focus, reason, clarity and overview), B subject fulfilled the criterion (reason and clarity), and $C$ subject fulfilld the criterion (situation). Based on the calculation of estimate parameter, the questions and GRM, all of three subjects have an average critical thinking ability with skill score between 1,00 until $-1,00$.

Keyword: Critical thinking, Graded Response Models.
\end{abstract}




\section{Pendahuluan}

Matematika merupakan salah satu mata pelajaran wajib yang diajarkan disemua jenjang pendidikan. Matematika memiliki peran penting dalam meningkatkan kemampuan berpikir (Anasha, 2013). Siswa yang telah mengikuti pembelajaran matematika diharapkan memiliki kemampuan berpikir kritis matematis.

Menurut Desmita (2009), kemampuan berpikir kritis adalah kemampuan merefleksikan permasalahan secara mendalam, mempertahankan pikiran agar tetap terbuka bagi berbagai pendekatan dan perspektif yang berbeda, tidak mempercayai begitu saja informasiinformasi yang datang dari berbagai sumber (lisan atau tulisan), serta berpikir secara reflektif ketimbang hanya menerima ide-ide dari luar tanpa adanya pemahaman dan evaluasi yang signifikan.

Kemampuan berpikir kritis matematis adalah kemampuan memecahkan masalah, menganalisis,mengevaluasi,membandingk an sesuatu dengan alasan yang baik, agar dapat mengambil keputusan yang terbaik dalam memecahkan masalah matematika. Kemampuan berpikir kritis matematis sangat penting dimiliki oleh para siswa, tetapi dalam kenyataannya masih banyak yang beranggapan bahwa untuk dapat berpikir kritis memerlukan tingkat kecerdasan yang tinggi. Menurut Khasanah (2015), kemampuan berpikir kritis siswa masih rendah, hal ini disebabkan oleh beberapa hal seperti, belum melibatkan siswa secara aktif, soalsoal matematika yang diberikan masih belum memungkinkan siswa untuk mengerjakan dalam berbagai cara yang sistematis, kesulitan para siswa untuk mengkomunikasikan ide-ide matematika mereka baik secara lisan maupun tulisan, siswa juga tidak maksimal dalam menganalisis soal-soal matematika. Rendahnya kemampuan berpikir kritis siswa juga dibuktikan dengan penelitian yang telah dilakukan oleh Novitasari (2012) yang menyatakan bahwa kemampuan berpikir kritis siswa SMP dalam membuktikan suatu pernyataan $16,12 \%$, kemampuan berpikir kritis siswa dalam memecahkan masalah 29,03\%, hal ini dikategorikan kemampuan berpikir kritis siswa masih rendah.

Rendahnya kemampuan berpikir kritis matematis dapat ditingkatkan dengan cara banyak berlatih soal. Butir-butir soal yang dibuat harus berbentuk uraian dan memuat tujuan yang dikaitkan dengan materi tertentu untuk mengukur kemampuan tersebut. Sampai saat ini, di Indonesia belum ada tes berpikir kritis yang terstandar dikembangkan dengan menggunakan setting yang umum, terutama dengan menggunakan pendekatan Item Response Theory (IRT) (Septarini, 2016). IRT adalah sebuah model probabilitas yang berusaha menjelaskan hubungan antara respon seseorang terhadap sebuah butir dengan variabel laten (kemampuan/ability atau sifat/trait) yang diukur oleh tes tersebut (Hendriani, 2016). Pada IRT soal tes benar-benar 
dapat mengukur tingkat kemampuan berpikir kritis siswa lebih akurat, begitu pula dalam mengestimasi parameter soal/butir. Ada dua jenis pendekatan di dalam model IRT yaitu pendekatan langsung dan pendekatan tidak langsung, model GRM termasuk dalam pendekatan tidak langsung. GRM adalah salah satu model Item Response Theory (IRT) untuk data politomus dengan sistem penskoran dimana tingkat kesukaran tiap kategori pada butir tes disusun secara berurutan sehingga jawaban peserta tes haruslah terurut dari kategori rendah hingga kategori yang tinggi.

Berdasarkan uraian di atas rumusan masalah pada penelitian ini adalah Bagaimana profil kemampuan berpikir kritis matematis siswa dengan menggunakan Graded Response Models? Sehingga penelitian ini dilakukan dengan tujuan untuk mengetahui profil kemampuan berpikir kritis matematis siswa dengan menggunakan GRM.

Penelitian ini bermanfaat untuk, bagi siswa, siswa dapat lebih mengasah pemikirannya dan dapat membiasakan untuk berpikir lebih kritis dalam mengerjakan berbagai soal uraian. Bagi guru, sebagai bahan pertimbangan bagi guru untuk lebih menggunakan soal uraian untuk membiasakan siswa agar lebih berpikir kritis. Selain itu guru juga dapat melihat kemampuan berpikir kritis siswa dengan model penskoran Graded Response Models. Bagi peneliti lain, sebagai acuan untuk melakukan penelitian lebih lanjut tentang kemampuan berpikir kritis matematis siswa.

\section{Metode}

Jenis penelitian yang digunakan dalam penelitian ini adalah penelitian kualitatif dengan pendekatan deskriptif. Penelitian ini dilaksanakan pada bulan Agustus, semester I pada tahun ajaran 2017/2018 dan bertempat di SMP Pangudi Luhur Salatiga yang terletak di Jalan Diponegoro 90 Salatiga. Populasi penelitian adalah siswa kelas VIII A SMP Pangudi Luhur Salatiga. Sampel penelitian ini adalah 3 orang siswa kelas VIII A, yaitu subjek $A$ berkemampuan tinggi, subjek $B$ berkemampuan sedang dan subjek C berkemampuan rendah. Teknik sampling yang digunakan adalah purposive sampling. Teknik pengumpulan data yang dilakukan dalam penelitian ini adalah teknik tes dan teknik non tes. Teknik tes dalam penelitian ini berupa tes tertulis. Tes tertulis dalam penelitian ini yaitu tes kemampuan berpikir kritis matematis dengan GRM. Teknik non tes dalam penelitian ini adalah wawancara.

\section{Hasil dan Pembahasan}

Tabel 1. Rekapitulasi Skor Tes

\begin{tabular}{|ccccc|}
\hline No Soal & Kode & \multicolumn{4}{c}{ Nama Siswa } \\
\cline { 2 - 5 } \multicolumn{1}{c}{1} & & $\mathrm{~A}$ & $\mathrm{~B}$ & $\mathrm{C}$ \\
\hline \multirow{3}{*}{1} & $\mathrm{P} 1$ & 2 & 1 & 1 \\
\cline { 2 - 5 } & $\mathrm{P} 2$ & 2 & 2 & 0 \\
\cline { 2 - 5 } & $\mathrm{P} 3$ & 1 & 0 & 0 \\
\hline & $\mathrm{P} 4$ & 1 & 1 & 2 \\
\hline & $\mathrm{P} 5$ & 2 & 2 & 0 \\
\hline & $\mathrm{P} 6$ & 2 & 0 & 0 \\
\hline & $\mathrm{P} 1$ & 2 & 1 & 1 \\
\hline
\end{tabular}




\begin{tabular}{|c|c|c|c|c|}
\hline & P2 & 2 & 0 & 0 \\
\hline & P3 & 0 & 0 & 0 \\
\hline & P4 & 1 & 1 & 1 \\
\hline & P5 & 2 & 0 & 0 \\
\hline & P6 & 2 & 0 & 0 \\
\hline \multirow[t]{6}{*}{3} & $\mathrm{P} 1$ & 2 & 1 & 1 \\
\hline & $\mathrm{P} 2$ & 2 & 2 & 0 \\
\hline & P3 & 0 & 2 & 0 \\
\hline & P4 & 2 & 1 & 2 \\
\hline & P5 & 0 & 2 & 0 \\
\hline & P6 & 2 & 0 & 0 \\
\hline
\end{tabular}

Berdasarkan tabel diatas P1, P2, P3, P4, P5 dan P6 merupakan kode untuk kriteria kemampuan berpikir kritis yaitu FRISCO. P1 adalah F (focus), P2 adalah R (reason), P3 adalah I (Inference), P4 adalah S (situation), P5 adalah C (clarity) dan P6 adalah O (overview). Dapat disimpulkan bahwa subjek A (berkemampuan tinggi) memiliki kriteria kemampuan berpikir kritis yaitu focus, reason, clarity dan overview. Subjek B (berkemampuan sedang) memiliki kriteria kemampuan berpikir kritis yaitu reason, dan clarity. Sedangkan subjek C (berkemampuan rendah) memiliki kriteria kemampuan berpikir kritis yaitu situation.

\section{A. Deskripsi dan Analisis Data Hasil Estimasi Parameter Butir Soal dengan Graded Response Models (GRM)}

1. Analisis Data Untuk Soal Nomor 1

Tabel 2.

Tingkat Kesukaran Soal Nomor 1

\begin{tabular}{cccc}
\hline No Soal & $\begin{array}{c}\text { Kode } \\
\text { Kriteria } \\
\text { Berpikir } \\
\text { Kritis }\end{array}$ & $\begin{array}{c}\text { Tingkat } \\
\text { Kesukaran }\end{array}$ & Keterangan \\
\hline 1 & P1 & 0,33 & Sedang \\
\cline { 2 - 4 } & P2 & 0,67 & Sedang \\
\cline { 2 - 4 } & P3 & 0 & Sukar
\end{tabular}

\begin{tabular}{|llll|}
\hline & P4 & 0,33 & Sukar \\
\cline { 2 - 4 } & P5 & 0,67 & Sedang \\
\cline { 2 - 4 } & P6 & 0,33 & Sedang \\
\hline
\end{tabular}

Tabel 2 menunjukan bahwa soal 1 memiliki tingkat kesukaran soal yang sedang dan sukar, yaitu P1, P2, P5, dan P6 dinyatakan memiliki tingkat kesukaran soal yang sedang dengan nilai tingkat kesukarannya adalah 0,67 dan 0,33. P3 dan P4 dinyatakan memiliki tingkat kesukaran soal yang sukar dengan nilai tingkat kesukarannya adalah 0.

Tabel 3.

Daya Pembeda Soal

\begin{tabular}{|c|c|c|c|}
\hline No Soal & $\begin{array}{c}\text { Kode } \\
\text { Kriteria } \\
\text { Berpikir } \\
\text { Kritis }\end{array}$ & $\begin{array}{c}\text { Daya } \\
\text { Pembeda }\end{array}$ & Keterangan \\
\hline \multirow[t]{6}{*}{1} & P1 & 1 & Baik sekali \\
\hline & $\mathrm{P} 2$ & 1 & Baik sekali \\
\hline & P3 & 0 & Jelek \\
\hline & P4 & -1 & Tidak baik \\
\hline & P5 & 1 & Baik sekali \\
\hline & P6 & 1 & Baik sekali \\
\hline
\end{tabular}

Tabel 3 menunjukan bahwa soal 1 memiliki daya pembeda soal yang tidak baik, jelek, dan baik sekali, yaitu P1, P2, P5, dan P6 dinyatakan memiliki daya pembeda soal yang baik sekali dengan nilai daya pembeda adalah 1. P3 dinyatakan memiliki daya pembeda soal yang jelek dengan nilai daya pembedanya adalah 0 . P4 dinyatakan memiliki daya pembeda soal yang tidak baik dengan nilai daya pembedanya adalah -1 .

Tabel 4.

Hasil Estimasi Parameter Butir Soal Nomor 1 dengan GRM

\begin{tabular}{|c|c|c|c|c|c|c|}
\hline \multirow[b]{2}{*}{$\theta$} & \multicolumn{5}{|c|}{$\mathbf{P}$} & \multirow[b]{2}{*}{ P6 } \\
\hline & P1 & P2 & 3 & P4 & P5 & \\
\hline
\end{tabular}




\begin{tabular}{|ccccccc|}
\hline $\mathbf{4}$ & 0,000 & 0,000 & 0, & 0,999 & 0,000 & 0,000 \\
$\mathbf{5}$ & 272 & 152 & 5 & 728 & 152 & 272 \\
\hline & 0,000 & 0,000 & 0, & 0,999 & 0,000 & 0,000 \\
$\mathbf{- 4}$ & 635 & 356 & 5 & 365 & 356 & 635 \\
\hline $\mathbf{0}$ & 0,363 & 0,242 & 0, & 0,636 & 0,242 & 0,363 \\
& 316 & 504 & 5 & 684 & 504 & 316 \\
\hline & 0,998 & 0,996 & 0, & 0,001 & 0,996 & 0,998 \\
$\mathbf{4}$ & 052 & 533 & 5 & 948 & 533 & 052 \\
\hline $\mathbf{4}$ & 0,999 & 0,998 & 0, & 0,000 & 0,998 & 0,999 \\
$\mathbf{5}$ & 166 & 515 & 5 & 834 & 515 & 166 \\
\hline
\end{tabular}

Berdasarkan tabel 4 diatas diperoleh hasil estimasi parameter GRM untuk soal no 1 masing-masing kategori $P$ memiliki nilai probabilitas kemampuan berpikir kritis matematis yang berbeda-beda sesuai dengan $\theta$ peserta yaitu $-4,5$ sampai 4,5.

Berikut adalah grafik hasil estimasi parameter butir soal no 1 dengan $\theta=-4,5$ sampai dengan 4,5.

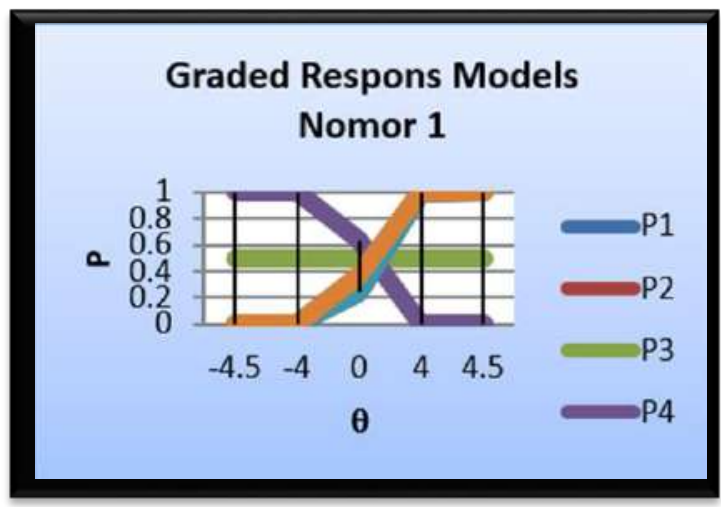

Gambar 1. Grafik GRM.

2. Analisis Data Untuk Soal Nomor 2

Tabel 5.

Tingkat Kesukaran Soal Nomor 2

\begin{tabular}{cccc}
\hline No Soal & $\begin{array}{c}\text { Kode } \\
\text { Kriteria } \\
\text { Berpikir } \\
\text { Kritis }\end{array}$ & $\begin{array}{c}\text { Tingkat } \\
\text { Kesukaran }\end{array}$ & Keterangan \\
\hline 2 & P1 & 0,33 & Sedang \\
\cline { 2 - 4 } & P2 & 0,33 & Sedang \\
\cline { 2 - 4 } & P3 & 0 & Sukar \\
\hline
\end{tabular}

\begin{tabular}{|cccc|}
\hline & P4 & 0 & Sukar \\
\cline { 2 - 4 } & P5 & 0,33 & Sedang \\
\cline { 2 - 4 } & P6 & 0,33 & Sedang \\
\hline
\end{tabular}

Tabel 5 menunjukan bahwa soal 2 memiliki tingkat kesukaran soal yang sedang dan sukar, yaitu P1, P2, P4 dan P5 dinyatakan memiliki tingkat kesukaran soal yang sedang dengan nilai tingkat kesukarannya adalah 0,33. P3 dan P4 dinyatakan memiliki tingkat kesukaran soal yang sukar dengan nilai tingkat kesukarannya adalah 0.

Tabel 6. Daya Pembeda Soal

\begin{tabular}{|c|c|c|c|}
\hline No Soal & $\begin{array}{c}\text { Kode } \\
\text { Kriteria } \\
\text { Berpikir } \\
\text { Kritis }\end{array}$ & $\begin{array}{c}\text { Daya } \\
\text { Pembeda }\end{array}$ & Keterangan \\
\hline \multirow[t]{6}{*}{2} & P1 & 1 & Baik sekali \\
\hline & P2 & 1 & Baik sekali \\
\hline & P3 & 0 & Jelek \\
\hline & P4 & 0 & Jelek \\
\hline & P5 & 1 & Baik sekali \\
\hline & P6 & 1 & Baik sekali \\
\hline
\end{tabular}

Berdasarkan tabel 6 menunjukan bahwa soal 2 memiliki daya pembeda soal yang baik sekali dan jelek, yaitu P3, P4 dinyatakan memiliki daya pembeda soal yang jelek dengan nilai daya pembeda adalah 0. P1, P2, P5, P6 dinyatakan memiliki daya pembeda soal yang baik sekali dengan nilai daya pembedanya adalah 1.

Tabel 7.

Hasil Estimasi Parameter Butir Soal Nomor 2 dengan GRM

\begin{tabular}{ccccccc}
\hline \multicolumn{8}{c}{$\mathbf{P}$} & $\mathbf{P}$ \\
$\boldsymbol{\theta}$ & $\mathbf{P 1}$ & $\mathbf{P 2}$ & $\mathbf{3}$ & $\mathbf{4}$ & $\mathbf{P 5}$ & $\mathbf{P 6}$ \\
\hline $\mathbf{-}$ & & & & & & \\
$\mathbf{4}$, & 0,0002 & 0,0002 & 0, & 0, & 0,0002 & 0,0002 \\
$\mathbf{5}$ & 72 & 72 & 5 & 5 & 72 & 72
\end{tabular}




\begin{tabular}{|ccccccc|}
\hline & 0,0006 & 0,0006 & 0, & 0, & 0,0006 & 0,0006 \\
$\mathbf{- 4}$ & 35 & 35 & 5 & 5 & 35 & 35 \\
\hline & 0,3633 & 0,3633 & 0, & 0, & 0,3633 & 0,3633 \\
$\mathbf{0}$ & 16 & 16 & 5 & 5 & 16 & 16 \\
\hline & 0,9980 & 0,9980 & 0, & 0, & 0,9980 & 0,9980 \\
$\mathbf{4}$ & 52 & 52 & 5 & 5 & 52 & 52 \\
\hline $\mathbf{4}$ & 0,9991 & 0,9991 & 0, & 0, & 0,9991 & 0,9991 \\
$\mathbf{5}$ & 66 & 66 & 5 & 5 & 66 & 66 \\
\hline
\end{tabular}

Berdasarkan tabel 7 diatas diperoleh hasil estimasi parameter GRM untuk soal no 2 masing-masing kategori $P$ memiliki nilai probabilitas kemampuan berpikir kritis matematis yang berbeda-beda sesuai dengan $\theta$ peserta yaitu $-4,5$ sampai 4,5.

Berikut adalah grafik hasil estimasi parameter butir soal no 2 dengan $\theta=-4,5$ sampai dengan 4,5.

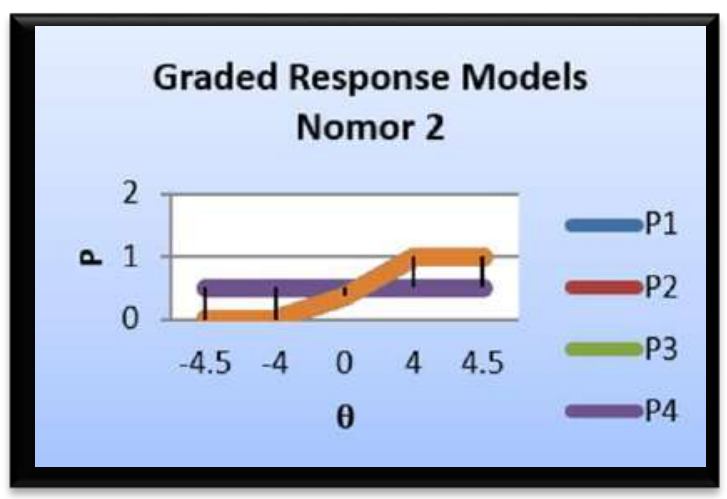

Gambar 2. Grafik GRM.

3. Analisis Data Untuk Soal Nomor 3

Tabel 8.

Tingkat Kesukaran Soal Nomor 3

\begin{tabular}{|cccc}
\hline No Soal & $\begin{array}{c}\text { Kode } \\
\text { Kriteria } \\
\text { Berpikir } \\
\text { Kritis }\end{array}$ & $\begin{array}{c}\text { Tingkat } \\
\text { Kesukaran }\end{array}$ & Keterangan \\
\hline 3 & P1 & 0,33 & Sedang \\
\hline P2 & 0,67 & Sedang \\
\hline & P3 & 0,33 & Sedang \\
\hline P4 & 0,67 & Sedang \\
\hline P5 & 0,33 & Sedang \\
\hline P6 & 0,33 & Sedang \\
\hline
\end{tabular}

Berdasarkan tabel 8 menunjukan bahwa soal 3 memiliki tingkat kesukaran soal yang sedang, yaitu P1 sampai P6 dinyatakan memiliki tingkat kesukaran soal yang sedang dengan nilai tingkat kesukarannya adalah 0,33 dan 0,67.

Tabel 9.

Daya Pembeda Soal

\begin{tabular}{|cccc|}
\hline No Soal & $\begin{array}{c}\text { Kode } \\
\text { Kriteria } \\
\text { Berpikir } \\
\text { Kritis }\end{array}$ & $\begin{array}{c}\text { Daya } \\
\text { Pembeda }\end{array}$ & Keterangan \\
\hline 3 & $\mathrm{P} 1$ & 1 & Baik sekali \\
\cline { 2 - 4 } & $\mathrm{P} 2$ & 1 & Baik sekali \\
\hline & $\mathrm{P} 3$ & 0 & Jelek \\
\hline $\mathrm{P} 4$ & 0 & Jelek \\
\hline $\mathrm{P} 5$ & 0 & Jelek \\
\hline $\mathrm{P} 6$ & 1 & Baik sekali \\
\hline
\end{tabular}

Berdasarkan tabel 9 menunjukan bahwa soal 3 memiliki daya pembeda soal yang baik sekali dan jelek. P1, P2, dan P6 dinyatakan memiliki daya pembeda soal yang baik sekali dengan nilai daya pembedanya adalah 1 . P3, P4, dan P5 dinyatakan memiliki daya pembeda soal yang jelek dengan nilai daya pembedanya adalah 0.

Tabel 10.

Hasil Estimasi Parameter Butir Soal Nomor 3 dengan GRM

\begin{tabular}{rrrrrrr}
\hline \multicolumn{1}{c}{$\mathbf{P}$} & $\mathbf{P}$ & $\mathbf{P}$ & $\mathbf{P}$ & \\
\hline $\boldsymbol{\theta}$ & $\mathbf{P 1}$ & $\mathbf{3}$ & $\mathbf{4}$ & $\mathbf{5}$ & $\mathbf{P 6}$ \\
\hline $\mathbf{4}$ & 0,00027 & 0,00015 & 0, & 0, & 0, & 0,0002 \\
$\mathbf{5}$ & 1575 & 2377 & 5 & 5 & 5 & 716 \\
\hline & 0,00063 & 0,00035 & 0, & 0, & 0, & 0,0006 \\
$\mathbf{- 4}$ & 5159 & 6436 & 5 & 5 & 5 & 352 \\
\hline & 0,36331 & 0,24250 & 0, & 0, & 0, & 0,3633 \\
$\mathbf{0}$ & 6111 & 401 & 5 & 5 & 5 & 161 \\
\hline & 0,99805 & 0,99653 & 0, & 0, & 0, & 0,9980 \\
$\mathbf{4}$ & 1996 & 3026 & 5 & 5 & 5 & 52 \\
\hline $\mathbf{4 ,}$ & 0,99916 & 0,99851 & 0, & 0, & 0, & 0,9991
\end{tabular}


5

6464

5216

Berdasarkan tabel 10 diatas diperoleh hasil estimasi parameter GRM untuk soal no 3 masing-masing kategori $P$ memiliki nilai probabilitas kemampuan berpikir kritis matematis yang berbeda-beda sesuai dengan $\theta$ peserta yaitu $-4,5$ sampai 4,5.

Berikut adalah grafik hasil estimasi parameter butir soal no 3 dengan $\theta=-4,5$ sampai dengan 4,5.

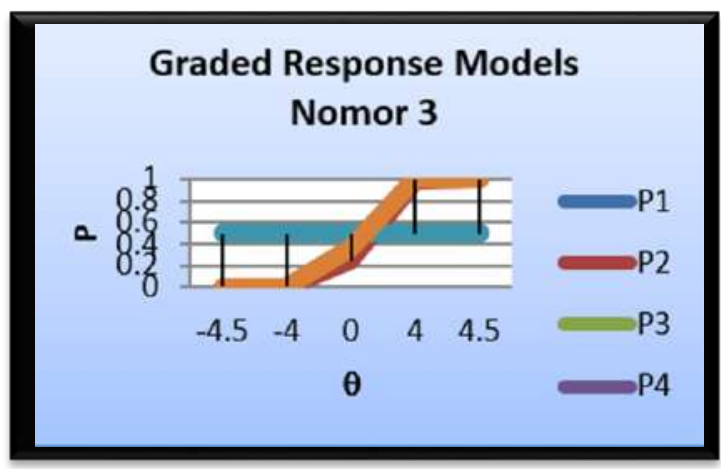

Gambar 3. Grafik GRM

Berdasarkan hasil skor yang diperoleh dari tes kemampuan berpikir kritis matematis siswa sesuai dengan rubrik penilaian yang telah disusun kemudian diolah menggunakan Microsoft Excel diperoleh tingkat kesukaran dan daya pembeda untuk masing-masing kategori $P$, kemudian hasilnya diolah dengan rumus GRM menggunakan Microsoft Excel. Soal no 1 berdasarkan grafik hasil estimasi parameter menggunakan GRM naik dari kemampuan peserta yang paling rendah yaitu $\theta \quad(-4,5)$ sampai peserta yang kemampuannya tinggi yaitu $\theta(4,5)$ untuk kategori tertentu. Soal no 2 berdasarkan grafik hasil estimasi parameter menggunakan GRM naik dari kemampuan peserta yang paling rendah yaitu $\theta(-4,5)$ sampai peserta yang kemampuannya tinggi yaitu $\theta(4,5)$ untuk kategori tertentu. Begitu juga untuk soal no 3 berdasarkan grafik hasil estimasi parameter menggunakan GRM naik dari kemampuan peserta yang paling rendah yaitu $\theta(-4,5)$ sampai peserta yang kemampuannya tinggi yaitu $\theta(4,5)$ untuk kategori tertentu.

Berikut adalah grafik hasil estimasi parameter butir soal no 1 sampai 3 dengan perhitungan GRM dari ketiga subjek:

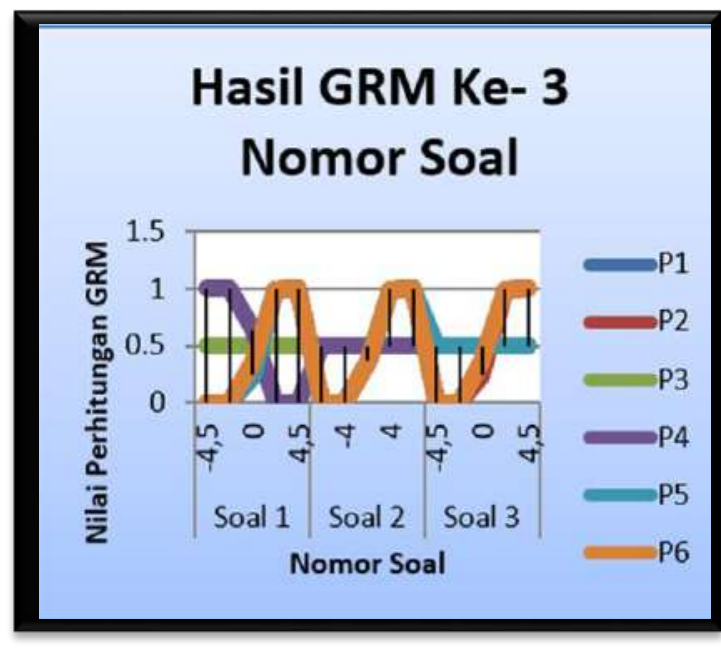

Gambar 4. Grafik GRM.

Berdasarkan gambar 4 estimasi parameter butir soal dengan menggunakan GRM yang telah dihitung diatas, dapat disimpulkan bahwa ketiga subjek memiliki tingkat kemampuan berpikir kritis yang sama, dengan nilai kemampuan berpikir kritis antara 1,00 sampai -1,00.

Tabel 11.

Kategori Kemampuan Berpikir Kritis Matematis 


\begin{tabular}{|cc|}
\hline Nilai Kemampuan & Interpretasi Kemampuan \\
\hline 3,00 sampai 2,00 & Sangat Tinggi \\
\hline 2,00 sampai 1,00 & Tinggi \\
\hline 1,00 sampai $-1,00$ & Rata-rata \\
\hline$-1,00$ sampai $-2,00$ & Rendah \\
\hline$-2,00$ sampai 3,00 & Sangat Rendah \\
\hline
\end{tabular}

Dengan menggunakan kriteria diatas, maka hasil estimasi parameter butir soal kemampuan berpikir kritis matematis ketiga subjek dalam 3 nomor soal yang telah dikerjakan kemudian diolah dengan GRM, menunjukan bahwa ketiga subjek memiliki kemampuan berpikir kritis matematis yang rata-rata.

Temuan lain dalam penelitian ini adalah subjek C memiliki kemampuan berpikir rendah hanya mampu menuliskan apa yang diketahui dan ditanyakan dalam soal, namun kemampuan tersebut dapat digolongkan berpikir kritis, terbukti dengan hasil penelitian yang menyatakan bahwa semua subjek memiliki kemampuan berpikir kritis yang sama yaitu pada tahap rata-rata. Subjek C memenuhi kriteria berpikir kritis yaitu situation.

Hasil penelitian sebelumnya yang telah dilakukan oleh (Sari, 2017) tentang Profil Kemampuan Berpikir Kritis Matematik Siswa Ditinjau dari Kemampuan Spasial dengan Menggunakan GRM. Hasil penelitian tersebut menyatakan bahwa siswa yang memiliki kemampuan spasial tinggi memiliki kemampuan berpikir kritis matematis yang tinggi, siswa yang memiliki kemampuan spasial yang sedang memiliki kemampuan berpikir kritis yang sedang dan siswa yang memiliki kemampuan spasial rendah memiliki kemampuan berpikir kritis yang rendah. Hasil penelitian ini adalah siswa yang memiliki kemampuan berpikir tinggi memiliki profil kriteria kemampuan berpikir kritis (focus, reason, , clarity dan overview). Siswa yang memiliki kemampuan berpikir sedang memiliki kriteria kemampuan berpikir kritis (reason dan clarity). Siswa yang memiliki kemampuan berpikir rendah memiliki kriteria kemampuan berpikir kritis (situation). Namun untuk kemampuan berpikir kritis ketiga siswa tersebut memiliki kemampuan berpikir kritis yang sama yaitu pada tahap rata-rata.

Berdasarkan kedua hasil penelitian yang telah dipaparkan diatas, siswa yang berkemampuan berpikirnya tinggi belum tentu memiliki kemampuan berpikir kritis yang tinggi, namun siswa yang memiliki kemampuan berpikir spasial yang tinggi memiliki kemampuan berpikir kritis yang tinggi. Kenyataan pada saat ini dimana siswa memiliki kemampuan berpikir kritis yang rendah masih banyak, dapat dikembangkan kemampuan berpikir kritisnya dengan cara banyak berlatih soalsoal spasial.

\section{Penutup}

Berdasarkan pembahasan diatas dapat disimpulkan bahwa subjek A (berkemampuan tinggi) memiliki profil kriteria kemampuan berpikir kritis yaitu focus, reason, clarity dan overview. Subjek B (berkemampuan sedang) memiliki kriteria kemampuan berpikir kritis yaitu reason, dan clarity. Sedangkan subjek C (berkemampuan rendah) memiliki kriteria kemampuan berpikir kritis yaitu situation. 
Hasil perhitungan estimasi parameter butir soal dengan GRM dari ketiga nomor soal yang telah dikerjakan ketiga subjek, dapat disimpulkan bahwa ketiga subjek memiliki kemampuan berpikir kritis yang sama dengan interpretasi kemampuan rata-rata dengan nilai kemampuan antara 1,00 sampai -1,00

Berdasarkan hasil penelitian ini, peneliti mengemukakan beberapa saran sebagai berikut:

Bagi Guru, hendaknya sering memberikan latihan-latihan soal yang dapat mengasah kemampuan berpikir kritis siswa khususnya pada materi matematika.

Bagi peneliti lain, penelitian ini terbatas pada teori mengenai Graded Response Models, bagi peneliti lain yang hendak menjadikan penelitian ini menjadi penelitian yang relevan sebaiknya lebih mengkaji lagi dan lebih dalam mengenai Graded Response Models.

\section{Daftar PUStaka}

Anasha, Z. (2013). Analisis Kemampuan Berpikir Kritis Matematik Siswa Dengan Menggunakan Graded Response Models. PROSIDING UNY.

Desmita. (2009). Psikologi Perkembangan Peserta Didik. Bandung : PT Remaja Rosdakarya

Hendriani. (2016). Pengembangan Tes Berpikir Kriris Dengan Pendekatan Item Response Theory. Jurnal Penelitian dan Evaluasi Pendidikan

Khasanah, N. (2015). Meningkatkan Kemampuan Berpikir Kritis Siswa Kelas VA. Jurnal UIN Surabaya
Novitasari. (2012). Meningkatkan Kemampuan Berpikir Kritis Dengan Berbantu Alat Peraga. E-jurnal UMS.

Sari, T. N. (2017). Profil Kemampuan Berpikir Kritis Matematik Siswa Ditinjau Dari Kemampuan Spasial Dengan Menggunakan Graded Response Models. Ejournal UIN Sunan Ampel.

Septarini. (2016). Pengembangan Tes Berpikir Kritis Dengan Pendekatan Item Response Theory. Jurnal Penelitian dan Evaluasi Pendidikan

\section{Riwayat Hidup PENULIS}

Gita Alexandra, S.Pd.

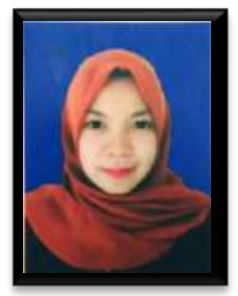

Lahir di Salatiga,26 Juni 1996 Studi S1 Pendidikan Matematika Universitas Kristen Satya Wacana, Salatiga, 2018. Informasi publikasi terbaik yang pernah dilakukan berupa jurnal skripsi.

Novisita Ratu, S.Pd. M.Pd.

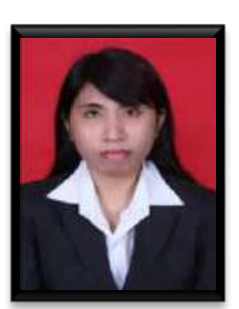

Lahir di Kupang, tanggal 07 November 1981. Dosen Program Pendidikan Matematika Universitas Kristen Satya Wacana, Salatiga. S1 Matematika Universitas Sanata Dharma Yogyakarta, S2 Manajemen Pendidikan Universitas Kristen Satya Wacana Salatiga. Presenter di AMD (Asian Mathematics Conference), dan mendapat Short Course dari Australia Award Fellowship di Sun Shine Coast University Australia. 
This page is intentionally left blank 